\title{
Carbon Trade Financing Strategies and Opportunities for Competitiveness of Private Sector SMEs in Uganda
}

\author{
Samuel Kalimunjaye ${ }^{1,2}$, Maurice Olobo ${ }^{1}$, Stephen Kyakulumbye ${ }^{1}$ \\ ${ }^{1}$ Faculty of Business and Management, Uganda Christian University, Kampala, Uganda \\ ${ }^{2}$ National Agricultural Research Organization/National Forestry Resources Research Institute, Kampala, Uganda \\ Email: kali.samuel@gmail.com, olobomaurices2005@yahoo.com,kyakusteve@yahoo.com
}

Received July 19, 2012; revised September 7, 2012; accepted September 15, 2012

\begin{abstract}
Availability of strategies and opportunities can drive SMEs competitive investment potential. In Uganda, several SMEs are emerging and their activities are having huge environmental impact hence contributing to global warming in form of carbon-dioxide release. There has been less effort to create awareness among public and private enterprises with an aim of reducing these negative effects. For example, water risks are rampant today, given population and climate change trends (www.ceres.org/), the demand for primary energy is projected to increase globally by a factor of 1.6 to 3.5 by the year 2050. Among developing countries, these factors are increasing from 2.3 to 5.2 (World Bank 2007). This study assessed corporate carbon financing strategies and competitiveness of small and Medium Enterprises with different management practices in Uganda. We used correlation analysis to find out whether there is significant relationship between company factors and competitiveness. The findings indicated Pearson correlation $r=0.435$. The result of $0.435^{* *}$ was found to be higher than the Pearson product -moment correlation coefficient critical values of 0.361 . This revealed that there was a positive and statistically significant relationship between Company factors and competitiveness of SMEs.
\end{abstract}

Keywords: Carbon Financing; Strategies; Opportunities; SMEs in Uganda

\section{Introduction}

Company factors define and determine the company's course in the future. A company will have only one company strategy but may incorporate into its concept several business strategies. Business managers need to leverage organizational resources beyond the normal business. This will be important in deriving carbon financing strategies which will determine competitive environment for companies, Small and Medium Enterprises in Uganda's carbon market.

The contribution of small firms towards innovation-led growth and job creation has been of great interest in Uganda. A large body of evidence shows that SMEs, especially young firms, contribute greatly and increaseingly to the innovation system by introducing new products and adapting existing products to the needs of customers on the market. In Uganda small and medium enterprises have increased across sectors ranging from production to marketing enterprises. This justifies the number of activities which make up these SMEs. The activeties of SMEs along the value chain represent a great deal of carbon footprint. i.e. Activities involving Carbon emissions contribute to carbon footprint and it is a measure of the impact a product or particular activity has on cli- mate change. This paper presents the literature review, methodology and data analysis, findings of the study, discussions and recommendations

\section{Literature Review}

Africa in general has come to witness a drastic rise in the number of Small and Medium Scale Enterprises to fuel her economic growth. However with the rising trends of Small and Medium Scale Enterprise, their contribution to climate change has varied from one SME to another in terms of volumes of production and emission levels. However by Definition as provided by the World Bank or International Finance Corporation (IFC), in terms of need for finance, the IFC defines an SME as: Small Enterprises: Loan Size of $\$ 10,000$ to $\$ 100,000$, Medium Enterprise: Loan Size of $\$ 100,000$ to $\$ 1$ million [1]. In Uganda more SMEs are emerging and many of the SMEs activities have contributed to global warming in form of carbon-dioxide release with less effort to reduce these negative effects. However, the extent to which investors include climate change in their mainstream investment decisions remains unclear [2].

There is a need to assist in the adaptation and development of pathways that will confront major causes of 
GHG emissions thereby utilizing the opportunities the African continent offers in consistency with regional and global sustainability goals [3]. Practices that integrated business environment should be aimed at increasing company profitability by introducing new socially responsible products or services. Reducing waste and adding new "social" value to existing products and services would one of those strategies in the right direction. Through such waste management, companies will be able to reduce their environmental impacts thereby raising awareness among Small and Medium Scale Enterprises on how they are impacting climate change.

[4] Observed that the global mean temperature averaged over land and ocean surfaces warmed by $0.76^{\circ} \mathrm{C} \pm$ $0.19^{\circ} \mathrm{C}$ between the first 50 years of the instrumental record (1850-1899) and the last 5 years (2001-2005) with a linear warming trend of $0.74^{\circ} \mathrm{C} \pm 0.18^{\circ} \mathrm{C}$ over the last 100 years (1906-2005)). The rate of warming over the last 50 years is almost double that over the last 100 years $\left(0.13^{\circ} \mathrm{C} \pm 0.03^{\circ} \mathrm{C}\right.$ vs $0.07^{\circ} \mathrm{C} \pm 0.02^{\circ} \mathrm{C}$ per decade). This reveals the impact human activity is having on the global climate patterns. It's therefore vital that as global citizens, there is need for sensitization on climate change and how human activity through business is aiding in escalating this trend. The message of Clean Development Mechanism is still a new concept in Africa and has to be continuously relayed on and on to be effective and widely accepted and adopted especially in Uganda.

The Clean Development Mechanism (CDM) has proven successful in generating emission reduction projects in many developing countries. As of end-2007, proceeds from the sale of emission credits from CDM projects amounted to about $\$ 7.4$ billion, a 50\% increase in value over 2006, and triple the value in 2005 . The overall carbon market has risen sharply over the past few years, reaching $\$ 60$ billions in 2007 or six times its value in 2005. However, Africa's share of CDM transactions is still relatively low with 5\% in 2007 [5]. This has shown the extent to which there is increased resistance to CDM due to the cost implication it has on businesses in Africa.

[6] states that the ILO's Green Jobs Programme promotes a practical and coherent strategy that recognizes the strong interdependence between the need for social development and the urgency to act on climate change. The analysis and policy guidance provided by the Programme contribute to promotion fair globalization and the development of sustainable economies which are efficient, socially just and environmentally sound. [7] Stipulates how competitiveness of a firm, cost-saving, qualityimproving and energy-saving investments needs to be undertaken.

According to OECD (2004), Small and medium-sized enterprises (SMEs) are a very heterogeneous group. SMEs are found in a wide array of business activities, ranging from single artisan producing agricultural implements for the village market, medium-sized automotive parts manufacturer selling to multinational automakers in the domestic and foreign markets. The diverse array of SMEs all impact on the climate change differently depending on the volumes of output generated as final products or services.

\section{Methodology}

In the study, a sample size of 100 randomly selected respondents composed of 70 customers and 30 employees from different SMEs sectors were selected for this study. The primary data was gathered from different employees, SME's and customers of different companies sampled in the study. Primary data was collected by using questionnaires. The questionnaire was constructed based on likert grading scale [8].

\section{Data Analysis}

Statistical Package for Social Scientists (SPSS) version 16.0 was used. Corporate carbon financing strategies and competitiveness of SME were assessed to understand how different factors affect competitiveness of SMEs; a principal axis factor analysis was performed. Factor analysis was based on the assumption that all variables are correlated to some degree. Factor analysis is an appropriate tool for grouping similar variables. All factors with eigen-values greater or equal to 1.0 and a minimum correlation coefficient greater than 0.33 contain a substantial amount of variation hence were retained for further analysis [9]. Factors were retained considering eigen-values greater than or equal to 1.0 and a minimum correlation coefficient greater than 0.33 . In order to minimize cross loading of variables, all variables with communalities less than or equal to 0.6 were excluded from the analysis to achieve the best grouping patterns.

Correlation analysis was performed to find out whether there was significant relationship between company competitiveness as a dependent variable and employee, customer factors as the independent variables. Competitiveness was determined based on market share, attitude and competence. Relationships that were significant at $95 \%$ confidence level $(p<0.05)$ were then subjected to multi regression analysis to assess the casual effect of combined factors on competitiveness.

\section{Findings of the Study}

Many factors enter into forming company strategy. Each exists within a complex network of environmental forces. These forces, conditions, situations, events, and relationships in form of planned actions over which the organization that has little control, collectively they form company operating environment. Below are descriptive sta- 
tistics presented in Table 1.

Findings from Table 1, the results of the study show that the majority of the respondents 46.7 percent agreed that they were aware of the strategies/plans on company climate change and 6.7 percent strongly disagreed. This is because many corporate companies are becoming aware of the climate change risks and opportunities associate with their company's activities and are putting measures in place to minimize their activity impact on the environment. The study also revealed that 20 percent of companies were missing out on the awareness avenues. Therefore, corporate strategies should be interested in as far as climate change issues are concerned. When the study assessed whether Plans were in place for investment in SMEs 33.3 percent agreed and surprisingly 26 percent of respondents disagreed. Also the study assessed the willingness of corporate companies to invest in SMEs. It was established that 43 percent of corporate companies have the willingness to invest in SMEs. The culture of SMEs should be built on specialized products and investment. This should be targeted at offering the market carbon trade opportunities such that it's easy for these corporate companies to determine areas of support to make the SMEs more competitive.

However, when asked whether the budgets were in place for tree planting, the study revealed that majority of the respondents 36.7 percent strongly agreed, with 0.0 percent undecided. The study revealed that tree planting $36.7 \%$ is major activity which provides companies with firewood as alternative sources of energy. The study also found out that several corporate companies have budgets for tree planting for the purpose of environmental awareness through corporate social responsibility. SMEs and corporate companies investments in tree planting could play a key role in the carbon trading systems in the near future especially when CDM, REDD and VCM fully embraced by corporate companies. This will depend on the innovation level of these corporate companies in the market.

The response on aspect of company plans, the study revealed there was interest to invest in energy. The majority 36.7 percent agreed with the statement, however, the undecided were 13 percent, 10 percent strongly agreed. Energy sources, supply and their effectiveness is important for the investment atmosphere and the performance of any economy because, most industry operations need efficient and adequate energy supply. SMEs need to take up such opportunities in the energy sector to broaden the energy industry through investing in the different energy sources because the companies are willing to support the energy initiatives.

Investment in water, the study revealed that 26.7 percent of respondents were undecided and 23.3 percent agreed that companies had plans to invest in water. Water resource in Uganda is sufficient to provide competitive environment for SMEs and this is justified by the mean value of 2.8 which is below average tending towards complete disagreement among respondent. But SMEs may be at risk when efforts to increase and protect water sources by corporate companies are not in place. It may undermine water availability and water quality in future given the level of company waste accumulation and disposal system. Most company waste is channeled in water bodies.

The study also evaluated company structures and marketing strategies whether consider carbon financing and planning. The results indicated that 26.7 percent of respondents were in agreement and 10 percent disagreed. It implies that carbon financing is a new concept that corporate companies are yet to embrace and understand. Carbon financing and planning in SMEs provide an opportunity for capital sources as more corporate companies take up interest in SMEs investment.

The response rate about company having systematic procedures for monitoring and controlling energy and fuel consumption, the study revealed 36.7 percent of respondents in agreement, 26.7 percent strongly disagreed and only 3.3 percent disagreed. When all the measures of company factors were aggregated into one index, they generated a mean of 3.3 and a standard deviation (StD)

Table 1. Showing how company factors affect competitiveness of SMEs.

\begin{tabular}{|c|c|c|c|c|c|c|c|}
\hline \multirow{2}{*}{ Statements on Company Factors } & \multicolumn{5}{|c|}{ Percentage Responses } & \multirow[t]{2}{*}{ Mean } & \multirow[t]{2}{*}{ StD } \\
\hline & SA & A & UD & $\mathrm{D}$ & SD & & \\
\hline awareness of the strategies/Plans on climate change & 33.3 & 46.7 & 10 & 3.3 & 6.7 & 3.97 & 1.098 \\
\hline Plans are there for investment in SMEs & 10 & 33.3 & 26.7 & 3.3 & 26.7 & 2.97 & 1.377 \\
\hline Budget are there for tree planting & 36.7 & 33.3 & 16.7 & 0 & 13.3 & 3.8 & 1.324 \\
\hline Company plans are there for investment in energy & 10 & 36.7 & 13.3 & 13.3 & 26.7 & 2.9 & 1.423 \\
\hline Investment in water & 10 & 23.3 & 26.7 & 20 & 20 & 2.8 & 1.289 \\
\hline Company structure and marketing strategies consider carbon financing and planning & 23.3 & 26.7 & 13.3 & 10 & 26.7 & 3.1 & 1.561 \\
\hline $\begin{array}{l}\text { Company has systematic procedures for monitoring and controlling energy and fuel consumption } \\
\qquad \text { Average Mean 3.3, Average StD } 1.37\end{array}$ & 20 & 36.7 & 13.3 & 3.3 & 26.7 & 3.2 & 1.518 \\
\hline
\end{tabular}

Source: Field Data. SA = Strongly Agree, A = Agree, UD = Undecided, D = Disagree, SD = Strongly Disagree. 
of \pm 1.37 . This implies that generally all respondents were in agreement towards the same though with some wide deviations in their views. To establish the relationship between company factors and competitiveness in SMEs, Pearson's Product Moment Correlation Coefficient preceded by testing for the linearity with scatter diagrams as seen in the Figure 1 was computed.

The linear pattern emerged between both variables revealing a relationship. Pearsons-Product moment correlation coefficient was computed following the formula;

$$
r_{x y}=\frac{n\left(\sum x y\right)-\left(\sum x\right)\left(\sum y\right)}{\left.\sqrt{\left\{\left(n \sum x^{2}\right)\right.}-\left(\sum x\right)^{2}\right\} \sqrt{\left\{n\left(\sum y^{2}\right)-\left(\sum y\right)^{2}\right\}}}
$$

where $n$ is the number of paired observations, $\sum x y$ is the sum of the gross product of company factors and competitiveness, $\sum x^{2}$ is the sum of all the squared values of company factors, $\sum y^{2}$ is the sum of all the squared values of competitiveness, $\left(\sum x\right)^{2}$ is the sum of company factors squared and $\left(\sum y\right)^{2}$ is the sum of competitiveness and squared and below are the results in Table 2:

From the Table 2, the study revealed the correlation between Company factors and competitiveness of SMEs. The findings indicated the Pearson correlation $(r=0.435$, $\mathrm{P}=0.016)$, $\mathrm{N}$ represents the number of respondents (30). The study revealed an $r=0.435^{* *}$, which is above 0.361 from person product-moment correlation coefficient critical values. Therefore this indicates a positive and statistically significant relationship between Company factors and competitiveness of SMEs. The implication of this is that when company factors are improved, there is likelihood that the SMEs will become competitive. It's because, as company factors improve better corporate strategies are developed which in turn leads SMEs to be more competitive because of the innovative environment among corporate companies.

\section{Regression Analysis}

A regression technique was used in order to determine the casual effect of combined factors on competitiveness, and results the study results are computed basing on the linear regression model of

$$
Y=\beta_{0}+\beta_{1} X_{1}+\beta_{2} X_{2}+\beta_{3} X_{3}+\cdots+\beta_{n} X_{n}+\varepsilon
$$

where $Y$ is the dependent variable, $X_{1-n}$ are the independent variables, $\beta_{0}$ is the constant, $\beta_{1-n}$ are the regression coefficients or change induced in $Y$ by each $X$ and $\varepsilon$ is the error. Below are the results in Table 3:

The Table 4 indicates the joint combination of all the factors above and how they predict competitiveness of SME's. R-squared of 0.233 implies that the change in competitiveness of a firm is determined by $23.3 \%$ of the studied factors. The remaining $76.7 \%$ is explained by other factors not covered in this study.

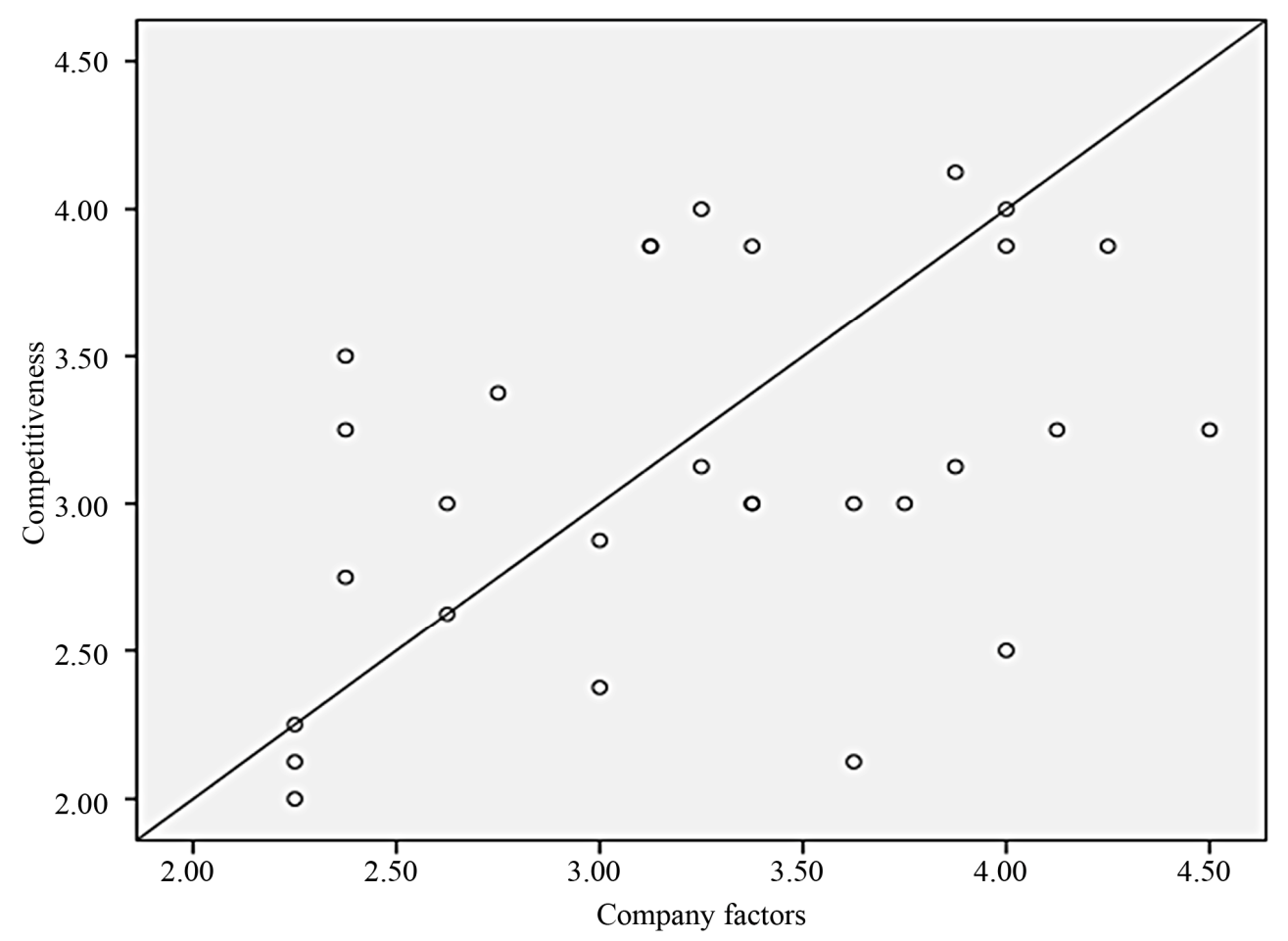

Source: Field data.

Figure 1. Competitiveness and company factor. 
Table 2. Correlation results between company factors and competitiveness in SMEs.

\begin{tabular}{cccc}
\hline & & Company Factors & Competitiveness \\
\hline \multirow{3}{*}{ Company Factors } & Pearson Correlation & 1 & $0.435^{* *}$ \\
& Sig. (2-tailed) & & 0.016 \\
& $\mathrm{~N}$ & 30 & 30 \\
Competitiveness & Pearson Correlation & $0.435^{* *}$ & 1 \\
& Sig. (2-tailed) & 0.016 & \\
& $\mathrm{~N}$ & 30 & 30 \\
\hline
\end{tabular}

${ }^{*}$ Correlation is significant at the 0.05 level (2-tailed).

Table 3. Model summary of regression results.

\begin{tabular}{ccccc}
\hline Model & R & R Square & Adjusted R Square & Std. Error of the Estimate \\
\hline 1 & $0.482^{\mathrm{a}}$ & 0.233 & 0.205 & 0.55669 \\
\hline
\end{tabular}

${ }^{\text {a }}$ Predictors: (Constant), Company Factors.

At this level, the study establishes that employee factors have the greatest casual effect on competitiveness of SMEs basing on sig. value $=0.008$; which is statistically significant because it's in the acceptable limits of 0.05 at $95 \%$ level of significance and 0.01 at $99 \%$ level of significance.

H0 $_{1}$ : Company factors do not have an effect on competitiveness of SMEs-Rejected.

$\mathrm{HO}_{2}$ : Employee factors do not relate to SMEs competetiveness-Rejected.

$\mathrm{HO}_{3}$ : Customer factors do not have an effect on SMEs competitiveness-Upheld.

\subsection{Discussion}

In March, 2009, the EU announced that the 105 billion euro was to be invested by 2013 to support the "green economy [10]. The study revealed that currently there are different market Segments which are being served by a number of business companies, SMEs and non-profit organizations. It's possible that through these segments, companies can invest in carbon-reduction projects both at community and enterprise level. These companies can in the end sell the emissions credits to buyers and final consumers [11]. However, to enhance opportunities for SMEs and Companies in carbon trade, there is a need to create an innovative structures which can accommodate business environment risk particularly those associated with climate change. Several scholars and researcher have stipulated that, new opportunities trends in global demand calls for action to tackle climate change by the World Business Council on Sustainable [12].

Corporate companies and organizations are becoming aware (46.77\%) of the climate change risks and opportunities associated with carbon trade. There are plans to advance carbon financing in Africa. For instance the world Bank (WB) paid US\$34,000 (€25,000) for the
Table 4. Multiple regressions results of all factors on competitiveness of SMEs.

\begin{tabular}{|c|c|c|c|c|c|c|}
\hline & \multirow{2}{*}{ Model } & \multicolumn{2}{|c|}{ Unstand Coeff } & \multirow{2}{*}{$\begin{array}{c}\text { Stand } \\
\text { Coeff }\end{array}$} & \multirow{2}{*}{$\mathrm{T}$} & \multirow{2}{*}{ Sig. } \\
\hline & & B & $\begin{array}{l}\text { Std. } \\
\text { Error }\end{array}$ & & & \\
\hline \multirow{5}{*}{1} & (Constant) & 1.350 & 0.650 & & 2.078 & 0.048 \\
\hline & Company Factors & 0.179 & 0.165 & 0.192 & 1.086 & 0.288 \\
\hline & Employee Factors & 0.423 & 0.146 & 0.519 & 2.896 & 0.008 \\
\hline & Customer Factors & -0.049 & 0.133 & -0.059 & -0.370 & 0.715 \\
\hline & (Constant) & 3.264 & 1.131 & & 2.886 & 0.009 \\
\hline \multirow{6}{*}{2} & Company Factors & 0.193 & 0.134 & 0.208 & 1.439 & 0.164 \\
\hline & Employee Factors & 0.369 & 0.119 & 0.453 & 3.091 & 0.005 \\
\hline & Customer Factors & -0.100 & 0.112 & -0.119 & -0.896 & 0.380 \\
\hline & Company Data & -0.780 & 0.243 & -0.438 & -03.210 & 0.004 \\
\hline & $\begin{array}{l}\text { Personal Background } \\
\text { Information }\end{array}$ & -0.087 & 0.263 & -0.045 & -0.332 & 0.743 \\
\hline & Policy Factors & 0.141 & 0.120 & 0.154 & 1.175 & 0.253 \\
\hline
\end{tabular}

${ }^{\mathrm{a} D e p e n d e n t ~ V a r i a b l e: ~ C o m p e t i t i v e n e s s . ~}$

purchase of carbon credits from the Humbo Community Based Forest Management Project in Ethiopia and pledged to buy credit for half of the $330,000 \mathrm{t}$ of carbon the forest can absorb, worth a total of US\$726, $000(€ 538,000)$ over 10 years [13]. This could provide and alternative income, capital and return for small and Medium enterprise. This in turn would improve the living and investment competitive conditions of rural based enterprises particularly those supporting rural based enterprises on forest, agriculture and packaging. This will help communities make a living from carbon trading instead of fire wood [14].

The will generated from climate change stakeholders ranging from employees and the customers, board of director or executives, banks and insurance companies globally, a record of 57 climate-related shareholder resolutions were filed with US companies, of which nearly half were withdrawn after the companies agreed to positive climate-related commitments [15].

It's possible for Companies to initiate carbon trade. 
These companies have instituted plans and budgets on tree planting hence mitigating climate change to some extent. This would be an opportunity for CDM, REDD+, voluntary carbon trading systems. Many of these companies are using Corporate Social Responsibilities Activities (CSCA) in developing their strategise to capture more of these customers for tree and fruit planting for the purpose of environmental awareness finally promoting company products. Coca cola as a company in Uganda, taking the lead has revealed through a study based on the employee and the customer response $26.7 \%$ and $50 \%$ respectively [16].

Therefore, companies are considering tree planting as major activity providing alternative sources of energy. However, this is having an impact on the climate as several companies consider tree planting as a major tool for environmental awareness through seasonal campaigns and corporate marketing strategies. In addition, of the 656 proposals filed by shareholders, 80 were related to the environment. The majority of the Environmental filings was focused on climate change and urged companies to reduce their carbon foot print. The support for such resolutions increased to nearly $20 \%$ average voting score, up from $17 \%$ in the previous year [17]. Nile breweries promote environmental protection through reducing the carbon and energy footprint by planting trees [18].

The energy sectors, sources, supply and their effectiveness remain demanding in Sub Saharan Africa and important for the investment atmosphere. The performance of any economy including most industry level operational needs remain competitive. SMEs need to take up opportunities in the energy sector to broaden the energy industry through initiating activities appropriate for investtors. To large extent companies are willing to support the energy initiatives; Deutsche Bank introduced energy-saving mortgage loans to customers for upgrading works of home energy conservation and renewable energy installations [19]. Considering the long-term goal of SMEs of staying in business, growth and profitability, there is an urgent need to be effective and compete in local and global markets. Therefore SMEs must be quick and flexible in their response to stakeholders' needs [20].

Carbon financing is a new concept which is just emerging among corporations and to be involved, there is need to first understand the implication of involvement. Carbon financing and planning in SMEs could provide an opportunity for capital sources as a result of more corporate companies picking up more paying investments with these SMEs. The sustainability criteria for carbon financing on a regional or sub-regional and country level could provide greater clarity for developers seeking to meet these criteria without undermining the role of national authorities. This can address the issue of engaging under represented developing countries into the global carbon market, providing stream of finance and contributing to overall sustainable development objectives among developing countries. Therefore there is need for a more robust understanding of the complex context of carbon development in the African region [21].

This study revealed that employee factors drive companies to develop strategies that could manage the challenges arising as a result of an over-exposure to either low or high carbon activities. However, there is need to understand that systemic risk in the financial systems and the macro instruments that might be designed and deployed to help restrain the build-up of risk are all part of this paradigm. The risk resulting from calculation and estimation of capital requirements for SMEs might undermine the competitiveness of the business environment for SMEs in Uganda.

Therefore, policy initiatives by governments in partnership with private sector create awareness and design policies that can provide negotiation platform, boost investor confidence for thereby guaranteeing sustainable investment environment. The Prime Minister of Malaysia, Datuk Seri Najib Tun Razak once announced that Malaysia has agreed to reduce its carbon dioxide emissions to $40 \%$ by 2020 [14]. This was a huge stride in the right direction for sustainable development. However some industrialists have maintained that cutting emission would have serious economic effects on emerging economies such P. R. China, India, Malaysia only to mention but a few. Such a slow down would mean a reduction in industrial output which would have ripple effect across all sectors.

\subsection{Recommendations}

In conclusion, companies should focus on planning and analyzing enterprises that form sustainable strategies towards SMEs and become very useful irrespective of company and SMEs segment. Focusing on competitive carbon trade activities in Sub Saharan Africa will be key to invite investors for foreign direct investment in the country which will be explained by direct use of market initiatives answering the emerging concepts in the areas of energy, manufacturing and agriculture projects.

Integrated approach to carbon trade could play a critical role in integrating the carbon trading systems to take advantage of the unique environment in the market. This will close the existing carbon gap in trading systems initiating adaption of innovative competitive strategies to market niches and segments in society and globally.

The proposed Integrated Carbon Financing Model (ICFM) in Figure 1 below could bring life to carbon market system and SMEs based on individuals experts, publicprivate sector institutions for direct involvement in carbon policy and market adjustment.

The model is developed focusing on government, 
business community, market and niche segments and Social values i.e. providing a clear mode for carbon investments and revenue, increasing the investor confidence, flexibility and carbon emission response strategy in the country and sub Saharan countries.

From the Figure 2 below the arrows indicate the lines of communication and investment pathways or commitment in the carbon markets in terms of carbon revenue, information exchange on carbon investment opportunities and regulations.

Investors need information based on their potential to invest including particular characteristics of the market segments and opportunities that exists with the market. For example resources related to investment may not need serious procedures resulting from the markets. It may require individual expertise which is to be targeted.

However, carbon regulatory framework could be applied to investments which provide stream of revenue to the investors that individual governments can benefit from such investments through taxes and revenue flow for economic development.

Therefore, all these will depend on the competitiveness factors such as competence, attitude and market share commanded by companies and SMEs. Governments need revenue and societies need income to improve on their standards of living. The business systems in finance and markets where major production systems to be supported with minimal marketing strategies and carbon markets are not different. However, the ICFM

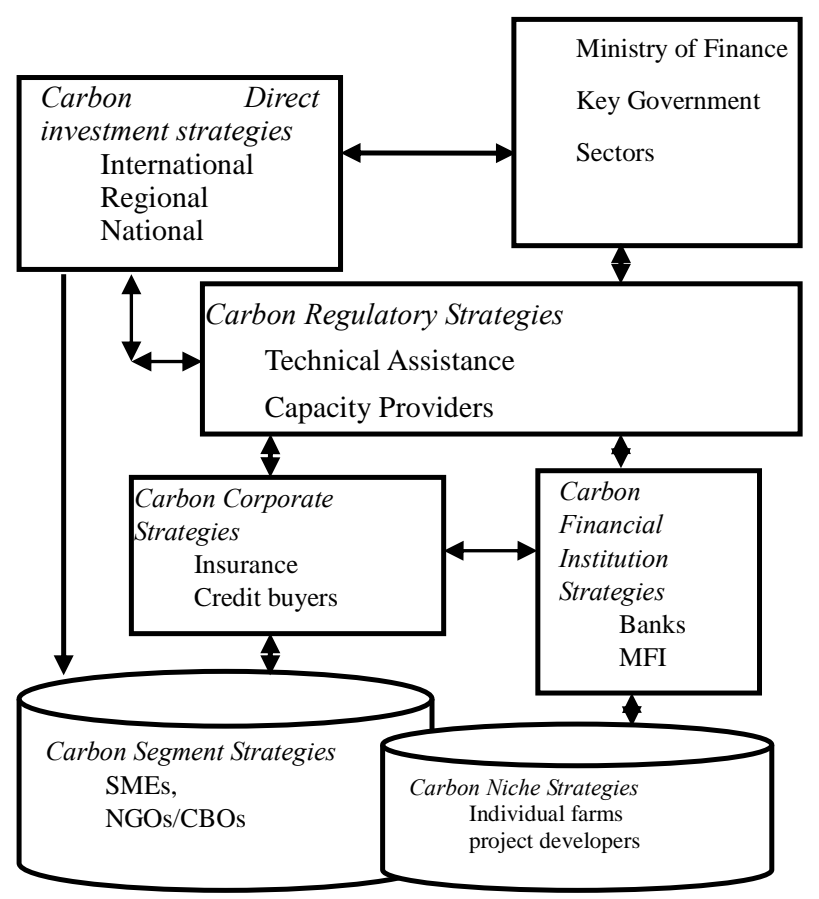

Source: Researcher.

Figure 2. Hypothetical integrated carbon financing model (ICFM). puts into 3 pillars:

1) Revenue generation for the country economy;

2) Generating participation for niches and segments in society to benefit from carbon trade;

3) Help developing sub Saharan African countries initiatives adapt carbon trade actions for wider capital and market gains.

\section{Conclusion}

The percentage effect of $21 \%$ in competitiveness signifies the importance of company factors as part of critical success factors and being tailored to achieving competitive environment to target the emerging opportunities such as carbon financing. Therefore, companies need operating plans, budgets and structures including the monitoring tools which determine the characteristics of critical success factors for a competitive strategy.

\section{Acknowledgements}

This paper is part of the master's thesis submitted by Samuel Kalimunjaye under supervision of Dr. Olobo Maurice and Stephen Kyakulumbye to School of Research and Post Graduate Studies for the award of Master of Business Administration of Uganda Christian University in Uganda in the year 2012. The master's study was partly supported by National Agricultural Research Organization/National Forestry Resources Research Institute (NARO/NaFORRI) under staff capacity building program.

\section{REFERENCES}

[1] Ministry of Finance Planning and Economic Development, "Uganda’s Draft Micro Small and Medium Enterprises Policy and Strategy,” 2007.

[2] C. Headland, "Has the Debate on Climate Change Affected Institutional Investment Behaviour," Headland Consultancy Report, Headland Consultancy Company, London, 2007.

[3] M. Karavai, "Conceptualizations of Sustainability in the Context of Voluntary Carbon Market,” Master of Science thesis, Lund University, Paradisgatan, 2009.

[4] S. Solomon, et al., "Technical Summary,” Working Group I: The Physical Science Basis, IPCC Fourth Assessment Report: Climate Change, 2007.

[5] http://www.oecd.org/

[6] International Labor Organization, “The International Labor Organization's Database on Small Enterprise Definitions, Policies, Laws and Regulations BASIS,” In: Contribution of Working Group I to the Fourth Assessment Report of the Intergovernmental Panel on Climate Change, Cambridge University Press, Cambridge and New York, 2011.

[7] A. Bigsten and K. Mugerwa, "Is Uganda an Emerging 
Economy?” Department of Economics, Göteborg University, Göteborg, 1999.

[8] M. Kavindra, "Success Factors For Knowledge Management," Master Thesis, International Business Management \& Consulting, University of Applied Sciences, Kempten, 2004.

[9] S. Gwali, "Taxonomic Diversity, Distinctness, and Abundance of Tree and Shrub Species in Kasagala Forest Reserve in Uganda: Implications for Management and Conservation Policy Decisions," Tropical Conservation Science, Vol. 3, No. 3, 2011, pp. 319-333.

[10] Y. C. Wen, "The Study on the Status and the Countermeasures of Low-Carbon Financial System of China, 2010. http://www.scirp.org/journal/lce

[11] M. Karavai, "Conceptualizations of Sustainability in the Context of Voluntary Carbon Market,” Master of Science thesis, Lund University, Paradisgatan, 2009.

[12] Shell Spring Board and Vivid Economics, “Opportunities for Innovation. The Business Opportunities for SMEs in Tackling the Causes of Climate Change,” 2006. http://sd-cite.iisd.org/cgi-bin/koha/opac-detail.pl?biblionu mber $=36019$

[13] The Spores, "Post Harvest Management Adding Value to Crops," 2011. http://spore.cta.int/index.php?option=com_content\&task= view\&lang=en\&id=1670\&catid $=9$

[14] J. Lopez, "Business should Lead against Climate Change, the Star,” 2010. http://biz.thestar.com.my/news/story.asp?file=/2010/1/14/ business $/ 5466364 \&$ sec $=$ business

[15] F. Bettina, et al., "Banking \& Climate Change-Opportunities and Risks,” An Analysis of Climate Strategies in More than 100 Banks Worldwide, Eidgenössische Technische Hochschule, Zurich, 2009, p. 19.

[16] S. Shames and S. J. Scherr, "Institutional Models for Carbon Finance to Mobilize Sustainable Agricultural Development in Africa," Co-Agriculture Partners, Washington, 2010, pp. 12-13.

[17] F. Bettina, et al., "Banking \& Climate Change-Opportunities and Risks," An Analysis of Climate Strategies in more than 100 Banks Worldwide, Eidgenössische Technische Hochschule, Zurich, 2009, p. 14.

[18] Uganda National Road Authority, “The Road Magazine Gayaza-Zirobwe Road Nearing Completion,” Monthly Publication Issue 003, Uganda National Road Authority, 2010.

[19] United Nations Environment Program Finance Initiative, "Finance Initiative, Innovative Financing for Sustainability," 2007. http://www.unepfi.org/

[20] P. Turyakira, “A Competitive Strategy for Small and Medium-Sized Enterprises in Uganda,” Proceedings of the 10th Annual Ben-Africa Conference, Nairobi, 30 August1 September, 2010.

[21] M. Karavai, "Conceptualizations of Sustainability in the Context of Voluntary Carbon Market,” M.Sc Thesis, Lund University, Paradisgatan, 2009. 